To the two existing pedigrees showing both of these diseases we have added four more. The existence of linkage is established. The probability that our results are due to chance is less than $4 \times 10^{-8}$. For example, in one pedigree the three living hæmophilic relatives of a colour-blind hæmophilie, namely, a brother, a first cousin twice removed, and a second cousin once removed, were also colour-blind, while five male relatives who might have been, but were not, hæmophilic, had normal vision.

In the six pedigrees there was one case of crossing. over, a colour-blind hæmophilic having a colourblind non-hæmophilic brother. There had been $28 \frac{3}{4}$ opportunities of crossing-over, so the frequency of crossing-over (after allowing for certain small corrections) is as likely to be below as above 5 per cent.

A full account will be published elsewhere. We have to thank a number of colleagues, and particularly Drs. Birch, Macfarlane, Madlener, Riddell and Wright, and the Medical Research Council, for their assistance. We should like particularly to acknowledge the cordial co-operation of many members of the families concerned.

Julia Bell.

J. B. S. HALDANE.

Galton Laboratory and

Department of Zoology,

University College,

London.

Oct. 15.

\section{Distortion of Iron and Molybdenum}

THE recent communication in NATURE by Túry and $\mathrm{Krausz}^{\mathfrak{1}}$ may be helpful regarding work on the plastic distortion of metals and, in particular, on the nature of the yield point. In their letter, Fig. 1, No. 2, shows a load-extension curve for molybdenum wire after a certain treatment and involving the use of nitrogen at $1,300^{\circ} \mathrm{C}$. for $20 \mathrm{sec}$. This curve closely resembles the well-known load-extension curve for iron and soft steel, apart from a horizontal portion at the top of the curve. Fig. 1, No. 1, shows a curve for wire treated in hydrogen only, but no such yield point is shown in this case. The shape of the curves may be partly due to the different treatments affect. ing the crystal size, and it would be useful to know the size of the crystals in the wire and to know the behaviour of iron wire after similar treatments. In this connexion, data ${ }^{2}$ given by Arrowsmith for 'Armco' iron show that for material in which the crystal width was approximately $0.11 \mathrm{~mm}$. did not have a marked yield point, but for a crystal width of approximately $0.07 \mathrm{~mm}$. there was a considerable yield. Curves given by Edwards and Pfeil ${ }^{3}$ suggest that for aggregates of iron crystals the marked yjeld may not occur when the crystals are wider than approximately $0.25 \mathrm{~mm}$. or $0.4 \mathrm{~mm}$.

In iron and soft steel, the remarkable yield is associated with the Piobert effect (also known as Lüders' lines) which has also been reported, but much less frequently, as occurring in non-ferrous metals (for example, in aluminium and copper, but I believe that the distortion may be rather different in such rases because of the absence of the marked yield, though possibly related). It has been attributed to the presence of a second constituent in the structure and, on the Continent, to the presence of thin films of cementite at the boundaries of the ferrite crystals forming a strong network of cementite. The network was assumed to take the applied load for stresses up to the yield point, at which it broke down, thus releasing the load on to the weaker and more ductilc crystals of ferrite which, as a result, extended immediately.

This I believe to be unlikely for several reasons ${ }^{5}$ and that, so far as is known, it seems probable that the yield in aggregates of iron erystals (Piobert effect) is due primarily to the mode of distortion of the single iron crystal together with small crystal size, and that the effect may occur in aggregates of crystals of other metals provided that the mode of distortion of the single crystal of the metal resembles that of iron, and that the crystals be very small. (Crystal size may be of great importance. Thompson and Milling. ton $^{8}$ attributed the distortion associated with the marked yield to certain kinds of motion in the body. centred cubic crystal, but it may occur in metals of dissimilar lattice because of the apparently unknown influence of crystal size.) Further, the effect shows a ready response of the aggregate of iron crystals to distort in a general way according to the internal distribution of stress, and it seems that the trans. mission (which results in the yielding) of the distortion throughout the aggregate is facilitated by the large number of planes in the body-centred cubic latticed erystals of iron on which slip may oceur, and also, if body-centred cubic crystals can distort on planes (those of maximum shear stress) other than crystal planes ${ }^{7}$ and again by crystal size.

This transmission, without 'jamming' as it were, would happen, presumably, if the crystal size be not too big or if the capability of the individual crystals to collaborate with the influence of the general stress distribution be relatively unlimited. (Of the possible slip-planes in iron there appear to be at least three types, $\{110\},\{112\}$ and $\{123\}$, and the number of types appears generally to be more than for other metals, whilst for $\beta$-brass the types appear to be $\{110\}$ and $\{112\}$. By symmetry, there are a large number of planes, some of which will be possible slip-planes in virtue of their proximity to the planes of maximum shear stress.)

A thorough investigation of the distortion associated with the Piobert effect in soft steel, using X.ray diffraction methods, is in progress here and, as yet, reveals distortion in the crystals, but without the appearance of 'preferred' orientation of erystal planes, and suggesting that the distortion within the aggre. gate is complex. Present work also consists in exam. ining the properties of aggregates of very. small crystals. C. F. Elam (Mrs. G. H. Tipper) concludes that there is no material difference between facts ascertained about the distortion of single crystals of iron and $\beta$-brass? ${ }^{7}$. Attempts were made here during the summer of last year to produce the Piobert effect in aggregates of body-centred cubic latticed crystals of $\beta$-brass, but the desired smallness of crystal size could not be produced, which was unfortunate; so work on molybdenum, rather than tungsten (both of similar lattice as the brass), has already been started.

Metallurgical Laboratories, F. W. Fkus.

University, Manchester. Sept. 28.

\footnotetext{
1 NATURE, 138, 331 (August 22, 1936).

$J$. Iron and Steel Inst., 110, 317 (1921),

$J$. Iron and Steel Inst., 112, 93, Fiz. 9 (1925).

"E. W. Fell, "The Piobert Effect in Iron and Soft Steel", J. Iim and Steel Inst., 132, 75 (1935).

J. Iron and Steel Inst., 133, 389P (1933)

J. Iron and Steel Inst., 103, 82 (1921). " "The Distortion of $\beta$-Brass and Iron Crystals", Proc. Roy. Soc.
A, 153, 273 (1936).
} 